\title{
A UNIDADE DE TERAPIA INTENSIVA NEONATAL POSSIBILITANDO NOVAS PRÁTICAS NO CUIDADO AO RECÉ M-NASCIDOa
}

\author{
Roberta COST A ${ }^{b}$, M aria Itayra PADIL HAc
}

\section{RESUMO}

Pesquisa qualitativa, com abordagem sócio-histórica. 0 objetivo é compreender como se instituíram as práticas de cuidado ao recém-nascido na U nidade de T er apia Intensiva N eonatal (UTIN) em F lorianópolis, na década de 1980. 0 contex to do estudo foi o H ospital Infantil J oana de G usmão. Os sujeitos foram profissionais de saúde que participaram da implantação da U T IN. Para análise dos dados utilizamos o método genealógico proposto por Foucault. I dentificamos quatro agrupamentos discursivos: M uita criança saiu ganhando com isso; A gente aprendeu a cuidar do recém-nascido, cuidando; Faltava um ol har mais científico para a assistência; Cuidado sensível, humanizado e individual izado. A implantação de uma unidade específica para o cuidado do recém-nascido resultou numa redução da morbi-mortalidade neonatal e na aquisição do conhecimento científico. Os discursos dos profissionais de saúde revelam que, desde os primórdios da UT IN, já havia uma preocupação com o cuidado sensível, humanizado e individualizado ao recém-nascido.

D escritores: U nidades de Terapia Intensiva N eonatal. Recém-nascido. N eonatologia. Cuidado da criança.

\section{RESUMEN}

Investigación cualitativa, con abordaje socio-histórica, objetivo comprender como se instituyer on las prácticas de cuidado al recién nacido en la U nidad de T erapia Intensiva N eonatal (UT IN ) en F lorianópolis, B rasil, en la década de 1980. EI contexto del estudio fue el $\mathrm{H}$ ospital Infantil J oana de G usmão. L os sujetos fueron profesionales de salud que participaron de la implantación de la UT IN. Para análisis de los datos fue utilizado el método genealógico propuesto por F oucault. Identificamos 4 formaciones discursivas: $M$ uchas niños salieron ganando con eso; A prendimos a cuidar del recién nacido, cuidando; Faltaba un mirar más científico para la asistencia; Cuidado sensible, humanizado e individualizado. L a implantación de una unidad para cuidado del recién nacido resultó en reducción de la morbimortalidad neonatal y adquisición del conocimiento científico. L os discursos de los profesionales de salud revel an que desde los primordios de la U T IN , existía preocupación con el cuidado sensible, humanizado eindividualizado al recién nacido.

D escriptores: U nidades de Terapia Intensiva $\mathrm{N}$ eonatal. Recién nacido. $\mathrm{N}$ eonatología. Cuidado del $\mathrm{N}$ iño. T ítulo: L a U nidad de Terapia Intensiva N eonatal posibilitando nuevas prácticas en el cuidado al recién nacido.

\section{ABST RACT}

This is a qualitative research with a socio-historical approach. It aims to understand how practices of care to the new born w ere established in a N eonatal Intensive Care U nit (N ICU) in F lorianopolis, B razil, in the 1980's. The study's context was the Child's H ospital J oana de G usmão. Interview ed for this research w ere health professionals that had a role in the N ICU implementation. T heanalysis of the data was performed using $\mathrm{F}$ oucault's geneal ogical method. F our discursivegroups were identified: $M$ any children had gains with that; We learned how to care for new borns; A more scientific view of care was lacking; Sensible, humanized and individualized care. The establishment of a specific unit directed to new borns resulted in a reduction in neonatal morbimortality and in the acquisition of scientific knowledge. The health professionals' speeches show that, since the beginning of theN ICU, therewas a concern with the sensible, humaniz ed and individualized care of the new born.

Descriptors: Intensive care units, neonatal. Infant, new born. N eonatology. Child care. T itle: N eonatal Intensive Care U nits make new practices possible in the care of new borns.

\footnotetext{
a Artigo extraído da tese de D outorado defendida em 2009 no Programa de Pós-G raduação em E nfermagem (PE N) da U niversidade Federal de Santa Catarina (UFSC).

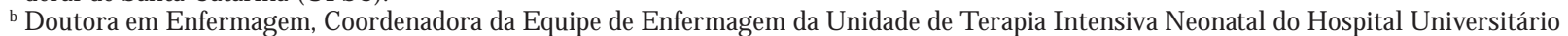
da U F SC, F lorianópolis, Santa Catarina, Brasil.

c D outora em E nfermagem, P rofessora A ssociada do D epartamento de E nfermagem e da Pós-G raduação da U F SC, Pesquisadora do Consel ho N acional de D esenvolvimento Científico e T ecnológico (CN Pq), F Iorianópolis, Santa Catarina, Brasil.
} 


\section{INT RODUÇÃO}

A preocupação com a assistência ao recémnascido na área da saúde surgiu como um prolongamento da obstetrícia. I nicialmente, as unidades de atendimento ao recém-nascido tinham por finalidade a manutenção e restauração das condições de vitalidade do recém-nascido, a prevenção de infecções e a diminuição da morbi-mortalidade. 0 objetivo do trabalho nestas unidades era promover a sobrevivência de bebês debilitados em sua adaptação à vida extra-uterina, justificando os investimentos econômicos e sociais para redução da mortalidade infantil e o novo poder-saber médico da neonatologia ${ }^{(1)}$.

Aos poucos, a preocupação exclusiva com a sobrevivência, foi se expandindo de modo a considerar não somente os aspectos biológicos e mensuráveis, mas também a qualidade de vida. As transformações no processo de trabalho visaram não só atender a necessidade social de diminuição da morbi-mortalidade, mas também, assegurar uma sobrevida de mel hor qual idade à mãe e ao neonato, esperando-se como produto final a manutenção e recuperação da força de trabalho para 0 setor produtivo da sociedade capitalista ${ }^{(1,2)}$.

A U nidade de Terapia Intensiva N eonatal (UTIN ) configura-se como um lócus de produção de saber e constitui-se em ambiente terapêutico apropriado para tratamento de recém-nascidos de risco, sendo considerada de alta complexidade(3). A incorporação de novas tecnologias, a necessidade de diferentes categorias profissionais, a presença cada vez mais frequente dos pais e o cuidado de bebês cada vez menores já fazem parte de uma realidade que exige novas práticas e novos sujeitos profissionais no cotidiano do hospital(4).

A pesar do significativo avanço na medicina e tecnologia, a prevalência de nascimentos prematuros ainda é bastante preocupante em todo mundo. Em países desenvolvidos, como a F rança (2004), ainda é de 6\%, enquanto nos Estados U nidos (2005) é de $11 \%$. Já nos países em desenvol vimento, como o Brasil (2005), a prevalência de prematuros é de aproximadamente 7\%(5). Diante deste contexto, a redução da mortalidade neonatal é um desafio mundial. A literatura atual reforça a idéia de que existe uma "tendência mundial à humanização da medicina de al ta tecnologia"(1-4,6). Os cuidadores da UTIN tiveram que aprender com os prematuros e os recém-nascidos de risco a aliar em seus cuidados a delicada interface entre os aspectos técnicos e os afetivos necessários para administrar a terapia que promova não somente a sobrevida de bebês organicamente sadios, mas também o seu desenvolvimento neurológico e a sua integração ao convívio familiar.

No Brasil, o M inistério da Saúde lançou, em 2000, a N orma de A tenção H umanizada ao recémnascido de baixo peso - M étodo Canguru, por meio da Portaria no 693 G M / M S ${ }^{(7)}$, que visa o estabelecimento de uma contínua adequação tanto na abordagem técnica quanto das práticas que impliquem em mudanças ambientais e comportamentais com vistas à melhoria na atenção aos prematuros, envolvendo a família.

E $m$ Santa Catarina, a partir da década de 1980, foram instaladas algumas UTINs em diferentes regiões do Estado, procurando descentralizar 0 atendimento especializado ao recém-nascido. Em F lorianópolis, os saberes e práticas no cuidado ao recém-nascido no âmbito hospitalar, começaram a ser desenvolvidos nos berçários das duas tradicionais maternidades da cidade, a $M$ aternidade $\mathrm{Dr}$. Car los Corrêa (1927) e a M aternidade Carmela D utra (1955). Entretanto, oficialmente a UT IN surgiu na cidade na década de 1980 , sendo que a primeira unidade foi instalada no Hospital Infantil Joana de G usmão (HIJG $)^{(8)}$.

A UTIN do HIJG foi inaugurada em 1987, por entender que muitos dos saberes e práticas instituídas no cuidado ao recém-nascido de risco em nosso estado foram influenciados pelo atendimento nesta unidade, decidimos realizar esta pesquisa com o objetivo de compreender como se instituíram as práticas no cuidado ao recém-nascido na UTIN em Florianópolis, na década de 1980, a partir do discurso dos profissionais de saúde.

\section{METODOLOGIA}

Pesquisa qualitativa, com abordagem sóciohistórica. N este estudo, adotamos os princípios da $\mathrm{N}$ ova história, uma história para o tempo presente, que nos lança a conhecer e compreender uma história-problema ${ }^{(9)}$. O ptamos por real izar esta investigação no HIJG, por ser este o H ospital de referência para 0 atendimento de crianças e recémnascidos de risco do estado de Santa Catarina e local onde foi implantada a primeira UTIN de FIorianópolis, Santa Catarina.

Para coleta de dados utilizamos a história oral, realizando entrevistas com os profissionais de saú- 
de que participaram do processo de implantação desta unidade. As entrevistas implicam na percepção do passado como algo que tem continuidade hoje, dentro de um processo histórico em andamento, cujo informante contribuirá com sua percepção dos fatos ${ }^{(10)}$.

Os sujeitos da pesquisa foram três médicos, cinco enfermeiras e cinco técnicos/auxiliares de enfer magem que trabal havam na UTI geral e/ ou UTIN. O período de coleta de dados foi de outubro de 2008 a março de 2009. Para garantir a anonimato, os sujeitos do estudo foram identificados com letras referentes às categorias profissionais e números.

Para análise dos dados foi utilizado o método genealógico proposto por Foucault. A genealogia seria o estudo das formas de poder: "[ ...] na sua multiplicidade, nas suas diferenças, na sua especificidade, na sua reversibilidade [ ... "111). A análise foi realizada inicialmente a partir das transcrições das entrevistas e posterior leitura atenta, onde buscamos extrair os enunciados, tentando conferir-lhes de imediato uma sistematização provisória. A pós compilação de todas as entrevistas, agrupamos os enunciados em formações discursivas provisórias. Construir um panorama geral ajudou-nos a orientar a re-leitura das entrevistas, possibilitando novas reconfigurações. Os focos de análise foram constituídos e organizados depois de ler, reler e perceber na interação com todas as entrevistas que apresentavam algumas regularidades a respeito dos significados que produziam. N esse percurso, realizamos agrupamentos discursivos, dando-Ihes significados a partir do referencial foucaultiano.

$\mathrm{O}$ projeto de pesquisa foi aprovado pelo Comitê de É tica em Pesquisa com Seres H umanos da U niversidade Federal de Santa Catarina sob protocolo $n=242 / 08$, folha de rosto 217903 , e pelo Comitê deÉ tica do HIJ G sob parecer $n^{\circ}$ 086/ 2008. Os participantes assinaram o Termo de Consentimento Livre e E sclarecido, conforme rege a Resolução 196/ 96 do Consel ho N acional de Saúde(12).

\section{RESULTADOS E DISCUSSÃO}

A análise das entrevistas possibilitou conhecer como se instituíram às práticas de cuidado ao recém-nascido em UTIN . E mergiram assim, quatro agrupamentos: $M$ uita criança saiu ganhando com isso; A gente aprendeu a cuidar do recémnascido, cuidando; Faltava um olhar mais cientí- fico para a assistência e; Cuidado sensível, humanizado e individualizado.

\section{M uita criança saiu ganhando com isso}

0 conhecimento de aspectos fisiológicos desses bebês direcionou as práticas de atenção a este segmento populacional. Percebemos que o foco do cuidado muitas vezes está direcionado apenas aos aspectos fisio-patológicos, em detrimento dos aspectos psico-sociais. A partir das entrevistas com os profissionais de saúde, podemos constatar que a implantação da UTIN possibilitou a produção do saber no cuidado ao recém-nascido.

0 cuidado mel horou muito. As crianças tinham qualquer piorinha no berçário já podiam descer por quetinham espaço. [ ...] foi a questão de abrir vaga. M uita criança saiu ganhando com isso. Com a evolução, da enfermagem, da medicina, dos equipamentos todos. A tresia de esôfago na UTI geral saiam pouquíssimos! $\mathrm{N}$ a neo sai a maioria. O utra doença que morria assim, a chance de viver era pouca era a hérnia diafragmática. M elhorou muito com a neo. Sem falar em membrana hialina!? (TE 2).

D e modo geral, a tecnologia é fundamental. Porque é super difícil controlar a temperatura do recém- nascido. A gente precisa da incubadora, de berço, de infravermelho, da fototerapia. A gente precisa de um surfactante [...] eu trabalhei na era antes de surfactante e depois na era do surfactante, então tem uma diferença muito grande na qualidade de vida, na sobrevida do recém-nascido prematuro (E 1).

$\mathrm{Na}$ fala dos sujeitos estão embutidas algumas características que parecem ter sido um divisor de águas na questão da complexidade assistencial: antes da era do surfactante ... depois da era do surfactante; assistência a crianças com atresia de esôfago, com hérnia diafragmática, com membrana hialina; equipamentos como incubadoras, fototerapia ... Enfim, o discurso dos profissionais revela a necessidade de um tipo de assistência que requeria aparatos tecnológicos mais complexos, possibilidades de intervenções cirúrgicas, qual ificação ou composição da equipe específica e organização da assistência, reforçando a importância do saber especializado.

Percebemos que com a implantação da UTIN, o profissional de saúde foi se apropriando do corpo do recém-nascido tornando este objeto de seu cuidado. Foucault coloca que, ao controlar o corpo do 
doente, o profissional exerce um poder sobre o outro e que esta relação de poder deve ser entendida como produtiva, pois produz saber e constrói discursos $^{(13)}$. N este sentido, as práticas de cuidado na UT IN possibilitaram a oper ação de um saber científico sobre o corpo do recém-nascido, este processo assemel ha-se ao que ocorreu com outros desenvolvimentos da Clínica, é fruto do conhecimento parcelar e especializado.

\section{A gente aprendeu a cuidar do recém-nascido, cuidando}

A partir do século XIX até os dias de hoje, com 0 avanço científico e tecnológico, o hospital constitui-se em um espaço terapêutico, inclusive de formação e produção de saberes que, numa linguagem científica, chamamos de conhecimento em saúde ${ }^{(14)}$. 0 saber clínico se estrutura e organiza o espaço, as relações e o fazer na UT IN , orientandoo para a intervenção sobre o corpo recém-nascido e funciona, ao mesmo tempo, como instância de produção de saber e, também, de formação profissional e de transmissão desse saber. E sse saber clínico que emerge se exercita, se amplia e subsidia vários outros tipos de saberes.

Ao serem interrogados sobre como era o cuidado na época da abertura da UTIN, muitos profissionais relataram que as práticas de cuidado foram melhorando a partir da experiência, no dia-adia da UTIN .

T ivemos treinamento de trabalho. E ntrava evinha trabalhar (TE 1).

[ ...] a gente não teve nenhum treinamento. A prendemos no dia-a-dia. A gente não sabia nem mexer numa incubadora. [ ...] F oi muito difícil no início, eu não tava acostumada a lidar com paciente daquele tamanho (E 2).

Os depoimentos evidenciam que quando abriu a UTIN, os profissionais de saúde não detinham um saber/ fazer específico, foi a partir da experiência de atuação nesta unidade que os profissionais foram adquirindo habilidade e destreza no manejo do neonato, e também a partir dos diagnósticos estabel ecidos que se buscou o conhecimento científico para embasar suas práticas. Salientamos aqui, que muitos dos profissionais que atuaram nesta unidade eram recém-formados e que a formação universitária tanto dos médicos, como das enfer- meiras é generalista, o que em nossa opinião contribuiu para esta aparente falta de preparo e habilidade dos profissionais para o cuidado do recémnascido. 0 domínio do saber pressupõe um poder, daquele que o domina, influencia e direciona as relações.

A questão da especialização merece destaque, uma vez que se institui uma unidade altamente específica e somente os médicos foram se especializar. A enfermagem não teve oportunidade 0 que resultou em grandes dificuldades e sofrimentos para estes profissionais. Criou-se um espaço específico para o desenvolvimento dos saberes e práticas médicas e a enfermagem também desenvolveu saberes e práticas especializadas, no entanto, sem apoio da Instituição e a reboque do saber médico. Porque nessa época, nesse lugar, não se considerava a enfermagem um saber científico, portanto, merecedor de aperfeiçoamento teórico.

No Brasil, a evolução da E nfermagem N eonatológica é um fenômeno recente. $\mathrm{Na}$ maioria dos Cursos de Graduação em Enfermagem, tradicionalmente 0 ensino do cuidado ao recém-nascido é realizado como unidade da D isciplina de Enfermagem Obstétrica ou da Enfermagem Pediátrica. $R$ aros são os cursos em que a E nfermagem N eonatológica é colocada no status de Disciplina e que conta com corpo docente específico. Convém lembrar que o Curso de G raduação não objetiva o ensino do cuidado ao recém-nascido de risco, devendo o mesmo ser objeto do curso de Especialização. Entretanto, no nosso meio, apenas em fins da dé cada de 1990 que começa a surgir este tipo de curso(15).

\section{Faltava um olhar mais científico para a assistência}

O conhecimento científico seria um conhecimento crítico, fundamentado e que visa produzir interpretações de realidade; permitindo certo grau de generalização, produzindo certo consenso sobre algo. É intencional porque constitui determinados objetos e pretende fornecer subsídios para compreendê-los ou produzir instrumentos de intervenção sobre eles. É um conhecimento sistematizado e que obedece às reg ras de um deter minado campo e, é também um conhecimento que se pretende verdadeiro ${ }^{(16)}$.

A partir deste entendimento, podemos inferir que o conhecimento científico é essencial para 
o profissional que atua na UTIN, possibilita um preparo adequado que sustenta a complexidades das práticas de cuidado desenvolvidas ao recémnascido de risco. Alguns profissionais destacam que quando abriu a UT IN a equipe era jovem com pouca experiência/ conhecimento no cuidado intensivo. Por outro lado, relatam que as práticas desenvolvidas desde o início da UT IN possibilitaram o aprimoramento científico e a habilidade técnica para o cuidar mais competente e individualizado.

A cho que teve uma grande revolução e evolução na assistência prestada ao recém nascido, nestes 20 anos. P rincipalmente no relacionamento entre os profissionais da saúde efamiliares e ao próprio paciente (M 1).

A gente fazia tudo que podia com as condições que se tinha. Talvez a gente tivesse que ter um olhar mais científico para aquela assistência, era muito o fazer por fazer. $N$ ão que a gente não soubesse o que estava fazendo, mas talvez faltasse um pouco de embasamento teórico, leitura (E 1).

Os depoimentos apontam para uma evolução do conhecimento, caracterizando que a partir da implantação da UT IN o saber e as práticas de cuidado foram se qualificando, possibilitando um meIhor atendimento, com enfoque principal no processo patológico e sobrevivência do recém-nascido. Por outro lado, alguns profissionais da saúde falam sobre a falta de embasamento teórico, de conhecimento científico, principalmente por parte dos profissionais de enfermagem. As enfermeiras, técnicos e auxiliares de enfermagem não tinham um saber especializado em relação ao cuidado, o que em nossa opinião, aparece nas fal as como a falta de um pensamento crítico, possivel mente porque na fala atual, ao lembrarem-se do passado, os profissionais são bastante críticos. 0 médico exercia o poder de orientar e determinar as práticas de cuidado.

As enfermeiras não detinham uma autonomia de saber próprio sobre o recém-nascido patológico. As práticas de enfermagem eram fundamentadas no saber clínico e resultavam de demandas colocadas pela ter apêutica médica, não se evidenciava um saber/fazer específico e autônomo, esse cuidado conforma-se como um cuidado prescritivo, que assume a forma de procedimentos técnicos ${ }^{(16)}$.

É importante, mencionar aqui que este período histórico caracterizou-se pela reformulação do papel do enfermeiro. Sendo que, em 1986 a legislação brasileira, promulgou a L ei do Exercício Pro- fissional, Lei no 7498/86, referente ao exercício da enfer magem, dispõe o A rt. 11, como atividades exclusivas do enfermeiro a "consulta de enfermagem; prescrição da assistência de enfermagem; cuidados diretos de enfermagem a pacientes graves com risco de vida; cuidados de enfermagem de maior complexidade técnica e que exijam conhecimentos de base científica e capacidade de tomar decisões imediatas"(17). Sob esse contexto, partimos da premissa que a sistematização da assistência de enfermagem deve ser incorporada à prática, como uma possibilidade relevante para a garantia da autonomia profissional e de um espaço próprio de cuidado de enfermagem.

Cabe ainda, destacar que nos depoimentos das enfermeiras percebemos pequenas mobilizações no sentido de instituir a sistematização da assistência de enfermagem na UTIN .

[ ...] a gente tentou fazer uma sistematização da assistência de enfermagem, defaz er tudo direitinho, mas aí foi se perdendo. P orque como que tu consegues fazer isso? Fazer com que as pessoas sigam aquela prescrição, se quando interna um, no final de semana ou a noite, aí não precisa. Porque eu vou obedecer no dia útil? $\mathrm{N}$ ão tem lógica. A sistematização ou ela éinstitucional ou ela fica assim ... uma coisa sol ta (E 1).

Entretanto, as prescrições não conseguiram ganhar corpo, seja pela falta de enfermeiras nas $24 \mathrm{hs}$, pela rotina de trabalho e principalmente, em nossa opinião, pelo poder médico hegemônico dentro do hospital, que foi contrário a este movimento, impossibilitando a enfermeira de exercitar sua autonomia.

[ ...] só tínhamos nós duas de enfermeiras, ficávamos só durante o dia, não tinha enfermeira nem a noite, nem final de semana (E 1)

0 exercício da autonomia do profissional de E nfermagem, só será possível quando este dominar o conhecimento de seu campo e da sua prática, utilizando-o, de maneira adequada na prestação do cuidado de E nfermagem. No cotidiano do hospital podemos afirmar que o profissional de saúde que detém o saber, é aquele que detém o poder.

\section{Cuidado sensível, humanizado e individualizado}

A tualmente, a humanização das unidades neonatais tem sido um objetivo perseguido pela neona- 
tologia, que reconhece o desequilíbrio flagrante entre o declínio da mortalidade e o aumento da morbidade dos recém-nascidos prematuros e de baixo peso ${ }^{(18)}$. N este processo, busca-se assegurar um cuidado pautado na abordagem humanística, associando os saberes técnicos e científicos ao cuidado humano.

A preocupação com a qualidade de vida, relacionada ao lado emocional do bebê, emergiu somente após vencer grandes dilemas e batalhas concernentes à diminuição de patologias da gravidez, as intercorrências do parto e às causas de óbitos neonatais, tanto do ponto de vista da Obstetrícia quanto da $\mathrm{N}$ eonatologia. A M edicina voltou-se para outras problemáticas, como: a relação mãefilho, estendida a seguir para o relacionamento paisfilho; a organização de um ambiente favorável ao desenvolvimento integral do individuo.

0 discurso dos profissionais com relação ao cuidado do recém-nascido reforça que desde os primórdios da UT IN busca-se a humanização, porém as práticas desenvolvidas dependiam de cada pessoa, de suas crenças e de seus valores. $\mathrm{N}$ a perspectiva destes profissionais, o cuidado enfatizava a abordagem biomédica, tendo a doença como foco central do cuidado. 0 recém-nascido era identificado por sua patologia, desconsiderando-se muitas vezes a sua história. 0 foco do cuidado estava nas técnicas, na sobrevivência do recém-nascido, na habilidade e na destreza do profissional.

Q uando eu entrei no Infantil, a gente ficou uma semana na U T I geral das crianças em treinamento, era um treinamento de como lidar com aparelhos, de como manusear aparelho da parte técnica (T E 4).

$\mathrm{N}$ ão existia norma e rotina. [ ...] M as seguia-se assim, algumas nor mas da U TI geral. [ ...] o cuidado mesmo prestado a criança ia da sensibilidade de cada um. $\mathrm{N}$ as tuas crenças, no que tu acreditavas (T E 4).

A necessidade da humanização dos cuidados no âmbito hospitalar existe em um contexto social no qual alguns fatores têm contribuído para a fragmentação do ser humano como alguém compreendido com necessidades puramente biológicas: a tecnologia, a visão de que é a equipe de saúde que detém todo o saber e, a ausência de percepção da integralidade do Ser Humano são exemplos destes fatores. 0 avanço da tecnologia médica, fez com que, por muitas vezes, o cuidado se tornasse a apli- cação de um procedimento técnico, a fim de cumprir com um objetivo mecanicista ${ }^{(19)}$.

A pesar desta visão biologicista e mecanicista, percebemos nos depoimentos dos profissionais de saúde que el es valorizavam o cuidado sensível, humanizado e individualizado, destacando que cada membro da equipe deveria ter sensibilidade para lidar com a hospitalização do recém-nascido, colocando o bebê como sujeito do cuidado, procurando individualizar 0 atendimento.

A tecnologia é necessária para proporcionar melhora na assistência e conseqüentemente aumentar a sobr evivência, mas não substitui alguns cuidados em relação a humanização e o respei to pelo paciente (M 1).

É e eu acho assim: o grupo de trabalho, ele precisa se modernizar, como equipe, valorizar o paciente, acima de tudo. $\mathrm{E} u$ acho que o grande ponto na área de saúde, no nosso caso, énunca se colocar acima do paciente. A gente não pode se colocar acima do paciente. A gente tem que colocar o paciente em 1 lo lugar (M 3).

Na UTIN, os profissionais de saúde precisavam ter a dimensão da importância referente à agilidade e destreza para realizar procedimentos, adquirir um conhecimento técnico-científico para um cuidado adequado, discernindo o fazer e como fazer, enxergando mais além do que os ol hos vêem, dialogando, tocando, sabendo ouvir e percebendo a linguagem não-verbal dos bebês. Portanto, percebemos que, nesse ambiente, os profissionais necessitavam ser motivados e sensibilizados para o cuidado amoroso ao bebê, deveriam cultivar o envolvimento, a flexibilidade e a singularidade para olhar as situações, buscando uma relação har mônica onde ambos possam juntos estimulando e sendo estimulados na busca do bem-estar ${ }^{(18)}$. E sta demanda colocava em cheque o saber biomédico no qual se assentava as práticas naUT IN. Este fator pode ser decisivo para o delineamento de novos saberes e novas práticas.

\section{CONCLUSÕES}

Com este estudo, podemos inferir que a implantação de uma unidade específica para o cuidado do recém-nascido de risco contribui para uma redução da morbi-mortalidade neonatal e na aquisição de conhecimento científico relacionado principalmente aos aspectos fisio-patológicos. Este processo possibilitou a instituição de novas práticas e 
sujeitos profissionais fazendo emergir novos problemas assistenciais geradores de novas configurações/ relações saberes e poderes.

Entretanto, os discursos dos profissionais de saúde revelam que desde o início da implantação da UTIN, já havia indícios da importância do cuidado sensível, humanizado e individualizado. Os profissionais de saúde neonatal foram levados a ter a dimensão da importância referente à agilidade e destreza para realizar procedimentos, somado ao conhecimento técnico-científico para discernir 0 fazer e como fazer, procurando particularizar as práticas de cuidado a cada recém-nascido e família.

Verifica-se, ao longo do tempo, a necessidade de transformações no processo de trabal ho nas UT IN s, com vistas a ampliar o objeto de ação para além do corpo do recém-nascido, por meio da inserção da família, assumindo o recém-nascido como um ser de relações, rumo à construção de um novo modelo assistencial que visa à humanização da assistência neonatal.

\section{REFERÊNCIAS}

1 Scochi CGS. A humanização da assistência hospitalar no bebê prematuro: bases teóricas para o cuidado de enfermagem [ tese] . Ribeirão Preto: E scola de E nfermagem de Ribeirão Preto, U niversidade de São PauI0; 2000.

2 Gaíva M AM, Scochi CGS. Processo de trabal ho em saúde e enfermagem em UTI neonatal. Rev LatinoAm Enfermagem. 2004;12(3):469-76.

3 Costa R. Saberes e práticas no cuidado ao recém-nascido em terapia intensiva na década de 1980 em F lorianópolis [ tese] . F lorianópolis: U niversidade Federal de Santa Catarina; 2009.

4 Costa R, M onticelli M . $O$ M étodo M ãe-Canguru sob o ol har problematizador de uma equipe neonatal. Rev Bras Enferm. 2006;59(4):578-82.

5 A raujo D M R, Pereira N L, Kac G. Ansiedade na gestação, prematuridade e baixo peso ao nascer: uma revisão sistemática da literatura. Cad Saúde Pública. 2007;23(4):747-56.

6 Pedron CD, Bonilha ALL. Práticas de atendimento ao neonato na implantação de uma unidade neonatal em hospital universitário. Rev G aúcha Enferm [ I nternet] . 2008 [ citado 2010 jul 25] ;29(4):612-8. D isponível em: http:/ / www.seer.ufrgs.br/index.php/ RevistaG auchadeE nfermag em/ article/ view/ 7633/ 4688.

7 M inistério da Saúde (BR), Secretaria de Políticas de Saúde, Área de Saúde da Criança. A tenção humanizada ao recém-nascido de baixo peso: método mãe canguru: manual do curso. Brasília (DF ); 2011.

8 Costa R, Padilha M I. 0 hospital infantil como marco no atendimento ao recém-nascido de risco em Santa Catarina (1987-2009). T exto Contexto Enferm. 2010; 19(3):469-78.

9 Le G off J, organizador. A história nova. 4ạ ed. São Paulo: M artins Fontes; 1998.

10 M eihy JCSB. M anual de história oral . 2a ed. São PauIo: L oyola; 2002.

11 Foucault $M$. Resumo dos cursos do Collège de F rance (1970 - 1982). Rio de Janeiro: Jorge Zahar; 1997.

12 M inistério da Saúde (BR ), Consel ho N acional de Saúde. Resolução 196, de 10 de outubro de 1996: diretrizes e normas regulamentadoras de pesquisa envolvendo seres humanos. Brasília (DF); 1996.

13 Foucault M. M icrofísica do poder. 3a ed. Rio de Janeiro: G raal; 1982.

$14 \mathrm{~K}$ ruse M HL. Os poderes dos cor pos frios: das coisas que se ensinam às enfermeiras [ tese] . Porto A legre: F acul dade de E ducação, U niver sidade Feder al do Rio Grande do Sul; 2003.

15 Kakehashi, TY. A situação atual da Enfermagem $\mathrm{N}$ eonatológica e suas tendências para o futuro. Acta Paul Enferm. 1996;9(n esp):17-22.

16 Dagmar EEM . Processos coletivos de produção de conhecimento em saúde: ol har sobre o exercício de enfermagem no hospital. Rev Bras E nferm. 2006;59 (1):95-9.

17 M inistério do T rabalho (BR). Lei n. 7.498, de 25 de junho de 1986: dispõe sobre a regulamentação do exercício da enfermagem e dá outras providências. Brasília (DF); 1986. 
18 Symington A, Pinelli J. Developmental care for promoting development and preventing morbidity in preterm infants. Cochrane Database Syst Rev. 2001;(4):CD 001814.
19 Barbosa IA, Silva M JP. Cuidado humanizado de enfermagem: 0 agir com respeito em um hospital universitário. Rev Bras Enferm. 2007;60(5):54651.
Endereço da autora / Dirección del autor / Author's address:

Roberta Costa

Rua Capitão Euclides de Castro, 371, ap. 203,

Coqueiros

88080-010, F lorianópolis, SC

E-mail: robertanfr@hotmail.com
Recebido em: 28/ 02/ 2011

A provado em: 31/ 05/ 2011 